\title{
$\mathrm{N}$-terminal Pro-brain Natriuretic Peptide plasma levels are Associated With a Short-Term Diagnosis of Cancer in Patients with Coronary Artery Disease
}

José Tuñón ( $\nabla$ jtunon@fjd.es)

Fundación Jiménez Díaz https://orcid.org/0000-0002-1373-0999

Álvaro Aceña

Fundación Jiménez Díaz: Hospital Universitario Fundacion Jimenez Diaz

Ana Pello

Fundación Jiménez Díaz: Hospital Universitario Fundacion Jimenez Diaz

Sergio Ramos-Cillán

Fundación Jiménez Díaz

Juan Martínez-Milla

Fundación Jiménez Díaz: Hospital Universitario Fundacion Jimenez Diaz

Oscar González-Lorenzo

Fundación Jiménez Díaz: Hospital Universitario Fundacion Jimenez Diaz

Jesús Fuentes-Antras

Hospital Clinico Universitario San Carlos

Nieves Tarín

Hospital Universitario de Móstoles

\section{Carmen Cristóbal}

University Hospital of Fuenlabrada: Hospital Universitario de Fuenlabrada

Luis Miguel Blanco-Colio

Hospital Universitario Fundación Jiménez Díaz: Hospital Universitario Fundacion Jimenez Diaz José Luis Martín-Ventura

Hospital Universitario Fundación Jiménez Díaz: Hospital Universitario Fundacion Jimenez Diaz

Ana Huelmos

Fundación Hospital Alcorcón: Hospital Universitario Fundacion Alcorcon

Carlos Gutiérrez-Landaluce

Hospital de Fuenlabrada: Hospital Universitario de Fuenlabrada

Marta López-Castillo

Fundación Jiménez Díaz: Hospital Universitario Fundacion Jimenez Diaz

Joaquín Alonso

Getafe University Hospital: Hospital Universitario de Getafe

Lorenzo López-Bescós 
Rey Juan Carlos University

\section{Luis Alonso-Pulpón}

Autonomous University of Madrid Faculty of Medicine: Universidad Autonoma de Madrid Facultad de Medicina

\section{Jesús Egido}

Hospital Universitario Fundación Jiménez Díaz: Hospital Universitario Fundacion Jimenez Diaz Ignacio Mahíllo-Fernández

Hospital Fundación Jiménez Díaz

Oscar Lorenzo

Hospital Fundación Jiménez Díaz

\section{Research}

Keywords: Coronary artery disease, N-terminal pro-brain natriuretic peptide, cancer, Tumor, Biomarker.

Posted Date: December 29th, 2020

DOl: https://doi.org/10.21203/rs.3.rs-135088/v1

License: (c) (7) This work is licensed under a Creative Commons Attribution 4.0 International License. Read Full License 


\section{Abstract}

Background N-terminal pro-brain natriuretic peptide (NT-proBNP) plasma levels are increased in patients with cancer. In this paper we test whether NT-proBNP may identify patients who are going to receive a future cancer diagnosis (CD) in the short term.

Methods We studied 962 patients with stable coronary artery disease and free of cancer and heart failure at baseline. NT-proBNP, galectin-3, monocyte chemoattractant protein-1, high-sensitivity C-reactive protein, high-sensitivity cardiac troponin I (hsTnl), and calcidiol (vitamin D) plasma levels were assessed. The primary outcome was new CD.

Results After 5.40 (2.81-6.94) years of follow-up, 59 patients received a CD. NT-proBNP [HR $1.036 \mathrm{Cl}$ (1.015-1.056) per increase in $100 \mathrm{pg} / \mathrm{ml} ; \mathrm{p}=0.001$ ], previous atrial fibrillation [HR $3.140 \mathrm{Cl}$ (1.196-8.243); $p=0.020]$, and absence of previous heart failure [HR $0.067 \mathrm{Cl}(0.006-0.802) ; p=0.033$ ] were independent predictors of a receiving a $C D$ in first three years of follow-up. None of the variables analyzed predicted a $C D$ beyond this time. A previous history of heart failure was present in $3.3 \%$ of patients receiving a $C D$ in the first three years of follow-up, in $0.0 \%$ of those receiving this diagnosis beyond three years, and in $12.3 \%$ of patients not developing cancer $(p=0.036)$.

Conclusions In patients with coronary artery disease, NT-proBNP is an independent predictor of CD in the first three years of follow-up but not later, suggesting that it could be detecting subclinical undiagnosed cancers. The existence of previous heart failure does not account for these differences. New studies in large populations are needed to confirm these findings.

\section{Full Text}

Due to technical limitations, full-text HTML conversion of this manuscript could not be completed. However, the latest manuscript can be downloaded and accessed as a PDF.

\section{Supplementary Files}

This is a list of supplementary files associated with this preprint. Click to download.

- AdditionalFile1.docx 